\title{
Australian Standards for Working with the Family in Palliative Care: Experiences from Practice concerning Implementing Organisational Change ${ }^{1}$ Naděžda Adámková, Michal Růžička
}

\begin{abstract}
The article provides practical experience of the multidisciplinary home hospice care team with organisational change. This change concerns the introduction of Australian standards for patient admission to home hospice care. The aim of the first phase of the research part was to map the current practice of admitting a patient to home hospice care, identify the needs of the team, and prepare the ground for the implementation of organisational change. Based on the obtained data, the team selected and agreed four standards for patient admission. These were implemented in practice in the next phase for a period of three months. The last phase consisted of a joint reflection upon the implementation process. The presented article describes in detail all the partial phases from the point of view of practical experience. At the end, it presents recommendations from which can be used by other organisations when optimising the progress of work in home hospice care teams.
\end{abstract}

Keywords: palliative care, home hospice, home hospice care, patient admission, multidisciplinary team

\section{Introduction}

Palliative care is a developing field that is gradually gaining ground as part of the care of clients of health and social services both abroad and in the Czech Republic ${ }^{2}$ - and is gradually establishing itself in discourses not only of medical science and ethics, but also of social work. ${ }^{3}$ In addition to hospice care, palliative care is increasingly being promoted as a human-centred approach not

1 This text is a modified version of the diploma thesis of Naděžda Adámková. It was successfully defended in 2018 at the Department of Management and Supervision, Faculty of Humanities, Charles University: : ( ) Univerzita Karlova, Domácí hospicová péče - možnost využití australských standardi̊ při príjmu pacienta (on-line), available at: https://dspace.cuni.cz/handle/20.500.11956/99678, cited 30 ${ }^{\text {th }}$ August 2020. Naděžda Adámková is also the author of the research work and the author of the tables.

2 Elizabeth DAVIES and Irene HIGGINSON, Palliative care: The Solid Facts, New York: World Health Organization, 2004; Ondřej SLÁMA, Paliativní a hospicová péče v České republice a v Evropě, Klinická onkologie 4/2009, pp. 183-185; Radka BUŽGOVÁ, Paliativni péče ve zdravotnických zařizeních: potřeby, hodnocení, kvalita života, Praha: GRADA, 2015.

3 Henk TEN HAVE and David CLARK (eds.), The Ethics of Palliative Care: European Perspectives, Philadelphia: Open University Press, 2002; Terry ALTILIO and Shirley OTIS-GREEN, Oxford Textbook of Palliative Social Work, Oxford: Oxford University Press, 2001. 
only in the institutional care environment ${ }^{4}$ but also as a type of health / social care provided in the patient/client's home environment. Although palliative care is gradually gaining the attention not only of the professional public but also of the lay public, this approach to human care in the last phase of one's life is still not widespread enough to be considered a commonly available and guaranteed health and social service. ${ }^{5}$

Although palliative and hospice care is increasingly being publicised today, many people have no idea what a 'hospice' is. The issue of death remains taboo, often evoking feelings of anxiety and fear. People are not used to talking about similar topics. Part of the population thinks that the patient belongs to the hospital. However, when treatment is stopped and the patient is sent home by a doctor, panic often occurs. Many patients do not have enough information about their next life journey with an incurable disease. Their general practitioner should be able to set up basic palliative care. If the care is not manageable at home, the patient is often sent back to the hospital. According to research from 2013, $78 \%$ of people would like to die at home. Unfortunately, the reality is that almost $60 \%$ of people die in hospitals, $20 \%$ in nursing homes, and about $20 \%$ at home or suddenly outside. ${ }^{6}$ The first author of the presented text is professionally involved in the field of palliative care as a nurse in a home hospice and as a coordinator of home hospice care. In her opinion, there is room in some areas for a more optimal organisation of team working procedures in her organisation. Therefore, she tried not only to analyse the process of admitting a new patient to home hospice care but also to implement a change that would lead to a higher quality of client care.

The presented article describes the practical experience of the multidisciplinary home hospice care team with organisational change. The team in the organisation where the research and experimental implementation of the change was originally formed had been created as a small group of volunteers - professionals, health professionals who wanted to help patients who are suffering at the very end of their lives. The team wanted to fulfil one of patients' last wishes - to die at home in the arms of the love of their own family. The team was originally small but due to the increasing demand of applicants for home hospice care it has grown into the current group of about thirty members. In the current team, the effective coordination of work is necessary. Otherwise, the resulting chaos could have a negative impact on the quality of care provided. For this reason, the team members themselves have consensually chosen several Australian palliative care standards for pilot implementation. The common goal was testing, resp. implementation of a change that would benefit both patients and the organisation itself. The primary purpose was to make the coordination of team work more effective and thus to increase the quality of services provided. The aim of the first phase of the research part was to map and analyse the current practice of admitting a patient to home hospice care in the researched organisation, to identify the needs of the team, and to prepare the ground for the implementation of organisational change. Based on the obtained data, four standards for the admission of the patient to home hospice care were consensually selected by the team. These were implemented in practice in the next phase for a period of three months. The last phase consisted of a joint reflection upon the implementation process and a collective assessment of whether the experience was beneficial for the team. The presented article describes in detail all the partial phases of this process from the point of view of practical

4 Karolína PECHOVÁ and Martin LOUČKA, Plánování péče v závěru života v pobytových sociálních službách pro seniory, Sociální práce / Sociálna práca 6/2019, pp. 112-126.

5 Ondřej SLÁMA, Ladislav KABELKA and Martin LOUČKA, Paliativní péče v ČR v roce 2016, Časopis lékařu českých 8/2016, pp. 445450 .

6 C) Cesta domů, o. p. s., Smrt a péče o umírající (on-line), available at: http://www.cestadomu.cz/res/data/053/006112.pdf, cited $9^{\text {th }}$ August 2017. 
experience. At the end, it presents recommendations which can be used by other organisations when optimising the progress of work in home hospice care teams.

\title{
Principles and Standards of Palliative Care
}

The most commonly used definition was expressed by the World Health Organization (WHO) which states that

Palliative care is an approach that improves the quality of life of patients and their families facing the problem associated with life-threatening illness, through the prevention and relief of suffering by means of early identification and impeccable assessment and treatment of pain and other problems, physical, psychosocial and spiritual. Palliative care: ${ }^{7}$

Another concise definition is that of the European Association for Palliative Care (EAPC):

\begin{abstract}
Palliative care is the active, total care of patients whose disease is not responsive to curative treatment. Relieving pain and other symptoms, and dealing with social, psychological, and spiritual problems is crucial. Palliative care is interdisciplinary in its approach and includes the patient, family and community. Palliative care honours and protects life. It considers dying and death to be a normal process. It does not accelerate nor delay death, though. It strives to maintain the maximum possible quality of life until death. ${ }^{8}$
\end{abstract}

All definitions have a common basis, namely the alleviation of suffering, dignity, maintaining the quality of life for the maximum possible period and all-round support for the patient and his loved ones.

At a general level, the standards are a set of recommendations of a general nature. They determine the minimum level of quality of care that should always be kept by facilities providing specialised palliative care. If the standards become part of the contract between the facility and the patient, they become binding.

The standards represent the basic starting points of hospice palliative care. They are principles, a target group, indications for hospice care, and basic organisational forms. The standards also contain a detailed plan of care for the physical, spiritual, mental, and social status. They contain ethical, legal, and cultural aspects of care as well. 'An integral part are personnel standards for in-patient and mobile hospices and material and technical equipment.'

Teams and individuals providing palliative care must be aware of the goals of hospice care. At work, they should use all their abilities, personal qualities, and the art of empathy when communicating with each individual patient. They should also assess and provide the patient with a dignified, professional accompaniment for the rest of his days. The essence of care is the quality and satisfaction of patient needs. The caring staff tries to gently involve the family and loved ones who are part of the patient's environment. The definition of quality of life is difficult to formulate as it changes throughout life. Professional staff are able to respond to the individual needs of a particular patient in an operative way. 'The basic principle for meeting the defined

Lukas RADBRUCH and Sheila PAYNE et al., Standardy a normy hospicové a paliativní péče v Evropě, Praha: Cesta domů, 2010 , p.16. Ibid, p. 16.

(c) APHPP, Hospice $v \check{C} R$ (on-line), available at: http://www.asociacehospicu.cz/wp-content/uploads/2017/01/STANDARDY\%202016. pdf, cited $9^{\text {th }}$ August 2017. 
goals is frequent communication not only with the patient but mainly with accompanying family members. ${ }^{10}$ Workers in this field must respect the life values of the patient even if they differ from the values of other people and their own ones.

In general, the division of palliative care into general and specialised palliative care is used at the basic level. Each of them has its specific purpose in providing specific services. It is mainly about nursing care and fulfilment of bio, psycho, social services, and providing psychological support to patients and their families.

General palliative care should be available in all facilities providing health services (according to the capacities and abilities of a non-specialist health facility) and such 'care should be provided by any health care professional, regardless of his expertise. ${ }^{11}$ Every health care professional should be able to detect and operatively adapt all processes important for improving the last moments of a patient's life.

We call professional interdisciplinary care specialised palliative care. It must be provided by a team of experts whose specialisation, education, and practice allow them to be prepared for providing precisely this care. A professional specialised team is usually a multidisciplinary group consisting of doctors, psychologists, nurses, carers, social workers, physiotherapists, occupational therapists, and clergy. A network of volunteers is often used to complement the team. The concept of specialised palliative care in the Czech Republic takes several forms: home palliative care - home/mobile hospice, in-patient hospice, palliative care department at in-patient medical facilities, palliative care counselling teams, specialised palliative care clinics, palliative care day-care centres, etc.

Home hospice teams provide care in a natural environment 24 hours a day. Availability and complexity are essential for the patient and family. These teams know where to call when needed. In case of such need they can obtain information about everything important, about the patient's condition. Thanks to this system, the team is able to help very quickly in the situation of sudden problems. Therefore, the home hospice is the most desirable form of patient care. Many of us would like to stay at home at such a time. 'The Czech Republic still has reserves in comparison with the world in this regard.' ${ }^{12}$ The 'hospice' in-patient facility takes care of patients who cannot stay at home. Palliative care departments are being set up in some healthcare facilities, such as hospitals and clinics. Specialised outpatient care is suitable for patients who are still able to come and then go home independently. It usually takes the form of a doctor's office and deals mainly with the treatment of pain. Day-care centres are intended for patients who are still able to visit these centres. The staff here offer activities that correspond with the patient's current strength, such as relaxation, exercise, and psychological support in the group of other clients. Outpatient medical facilities are suitable for patients who can easily transport themselves to such a facility, so they are not yet bedridden. In this condition, they can also visit day-care centres. They decide for themselves when they will come and how long they will be able to stay. The regularity of their visits depends on the current state and needs. Another important form of assistance in this care is various counselling centres. The centres direct patients or their relatives to other existing organisations that will help them in their difficult situation. These can be volunteer centres, medical equipment rentals, various hotlines, and associations specialising in this field.

10 Radek PTÁČEK and Petr BARTƯNĚK et al., Eutanazie - pro a proti, Praha: Grada, p. 64.

11 Alena ŠAFRÁNKOVÁ and Marie NEJEDLÁ, Interní ošetřovatelství II, Praha: Grada, 2006, p. 57.

12 Marie SVATOŠOVÁ, Hospice a umění doprovázet, Kostelní Vydří: Karmelitánské nakladatelství, 2011, p. 31. 


\section{Admission of the Patient to the Home Hospice}

As we deal here with the issue of admitting a patient to the care of a home hospice on a practical level, we will now approach the environment of the implemented project in this chapter. A necessary precondition for admission to a home hospice is the patient's wishes and consent to be taken care of in his home environment. The family or loved ones must be able to care for the patient at home. The patient's general practitioner should be willing to cooperate, especially in prescribing medications and devices. All participants understand the clinical situation in the same way; they are aware of the fact that the patient is terminally ill. The goal of care is to maintain a good quality of life in the home environment. All practical aspects of care are manageable at home, including dealing with acute or critical situations.

The patient comes into the care of a home hospice at the stage when he no longer knows how to cope with the situation at home and even his loved ones can no longer manage the care themselves. Sometimes it is this serious condition that forces them to apply for home hospice care. Unfortunately, the waiting time is often longer and the hospice does not have the capacity to receive the applicant immediately. Therefore, it is advisable to submit an application in advance even if the patient does not eventually use the service. The home hospice team receives the patient most often at the time of irreversible or terminal disease. The prognosis of the survival of these patients is usually days and weeks, exceptionally months.

The conditions for the admission of a patient to a home hospice include, in particular, that he suffers from an incurable disease in an advanced or final stage, has been acquainted with his state of health and has adequately understood his condition. Furthermore, he needs to understand the principles and limits of home hospice care and to agree with care in the home environment. The doctor decides on admission based on the categorisation of the patient's health condition.

The necessary conditions for the admission of a patient to a home hospice include the full information of caregivers about the patient's state of health. Caregivers should, with respect to their abilities, understand the prognosis of the disease, know the limits of home hospice care, and agree to the cooperation with the home hospice team. It is essential that at least one person can take responsibility for the continuous care of the patient.

\section{Research Part and its Goals}

The research took place in an organisation that provides health and social services in accordance with applicable legislation (that is, in accordance with Act No. 372/2011 Coll., On health services, and Act No. 108/2006 Coll., On social services). Specifically, these are residential and outreach services, a day care centre, and social counselling. We are talking about an organisation whose main goal is to provide care for terminally ill and dying patients. This service also includes care for loved ones, carers, and family members of the sick. The organisation was founded by representatives of the three churches and is based on the humanistic, Christian foundations of Western civilisation. It also represents the meaning of 'agape = unconditional love' of the Father, the Son and the Holy Spirit, which is based on the Bible. The main operation of the organisation, an in-patient hospice, was launched in 2008. Its main goal is to provide hospice, palliative care, that is, providing and improving comprehensive hospice care which will not be limited by the place of residence or social status of the patient.

It follows the standards of palliative care issued by the Czech Society for Palliative Medicine. The aim of hospice care is to alleviate pain, minimise the symptoms of an incurable disease, preserve 
the dignity of the patient, take care of the patient's mental state, and support the care and accompaniment of his family members or loved ones.

The general goal of the project implemented within this organisation was to find out the possibilities of optimising the procedure of a multidisciplinary home hospice team. This procedure involved admitting a patient to home hospice care while using the Australian standards for working with the family. This process consisted of three consecutive parts: (1) analysis and mapping of the patient admission process to home hospice care, (2) participatory implementation of the Australian patient admission standards, and (3) reflection upon the obtained experience.

\section{Course of Project Implementation, Questions on Methodology}

The research involved ten members of a multi-professional home hospice care team (two doctors, three social workers, one head nurse, and four nurses). The other professions of the team usually are involved with the care only after the admission of the patient, therefore, they were not included among the research participants.

Throughout the research, great emphasis was placed on an ethically responsible approach to the respondents; as it was an almost unique project in a relatively small but very specific team, we had to ensure that their identity and privacy were protected. A semi-structured individual interview was chosen as the main method of data collection, and a group interview was chosen for the final phase of evaluation of the implementation.

The research was divided into five basic stages and then into partial steps.

\section{Table 1: Implementation of participatory organisational change}

\begin{tabular}{|l|l|}
\hline \multicolumn{2}{|l|}{ Presentation of the research plan to the members of the multidisciplinary team } \\
\hline 1A & familiarisation with the Australian standards \\
\hline 1B & duration of the research \\
\hline 1C & answering questions by the researcher \\
\hline 1D & setting rules - ethics of research, cooperation, etc. \\
\hline Analysis of the process of admitting a patient to home hospice care \\
\hline 2A & individual semi-structured interviews \\
\hline 2B & environment mapping \\
\hline 2C & identification of team needs \\
\hline 2D & preparation of the ground for implementation \\
\hline Discussion on implementation settings \\
\hline 3A & selection of specific standards for implementation \\
\hline 3B & setting implementation rules and conditions \\
\hline Implementation \\
\hline 4A & implementation process - discussion during joint meetings \\
\hline 4B & conclusions to the individual standards \\
\hline
\end{tabular}




\begin{tabular}{|l|l|}
\hline \multicolumn{2}{|l|}{ Group interview } \\
\hline $5 \mathrm{~A}$ & conclusions of the group interview \\
\hline $5 \mathrm{~B}$ & reflection and recommendations of the researcher \\
\hline
\end{tabular}

Source: Own processing

In the first stage of the work (phases 1A-1D), the researcher presented the plan of the entire research at a regular meeting of the home hospice team. She gave the team members a translation of the individual Australian standards. The team members' goal was to study them and assess their possible suitability for use in their organisation. The team members were informed about the time burden that research collaboration would represent for individuals. Related questions were answered during a joint discussion.

In the second stage, individual semi-structured interviews took place. They were focused on the course of the first contact with the patient and his family. During the first interviews, the researcher realised that the questions would need to be adjusted with regard to the assumption of the existence of individual subcultures in the team. The first, very coherent group speaking the same language' was made up of nurses. The second group consisted of doctors and psychologists and the third, most heterogeneous group consisted of social workers, workers in aids rental business, and field workers. The aim of this stage was to map and analyse the current process of admitting a patient to a home hospice, identify the needs of the team, and prepare the ground for the implementation of the selected Australian standards.

In the third stage, a discussion took place at a regular meeting of the team. By consensus, it was determined which specific standards would be used for testing and which of the team members would be willing to participate in the implementation.

In the fourth stage of the research, a three-month implementation of the selected standards took place. At the same time, the team's discussions took place at regular meetings. The positives and negatives of the newly acquired experience were discussed.

In the fifth stage, after the implementation, a group interview of the participating team members was organised.

\section{Stage No. 2 (2A-2D): Analysis of the Patient's Admission to Home Hospice Care}

In June and July 2017, individual interviews were held with ten members of the multidisciplinary team. The aim of this (research) stage was to find out what the individual possibilities of the patient's first contact (applicant for home hospice care) were with the home hospice care team, and to analyse how the contact would take place.

\section{Respondent's personal procedure when admitting a patient to home hospice care}

The interviews revealed the usual individual procedure of the respondent when admitting a patient to home hospice care. Almost all the members of the team except one agreed that they had their own, relatively stable system. They are mostly guided by experience from their own practice and, instructed by the mistakes of themselves and their colleagues, they try to bring their own procedure to perfection. Where appropriate, they have taken over the established procedure from their predecessor and it suits them. They have trained in their procedure so that they cannot forget anything significant. Nine respondents follow the guidelines of the organisation for the 
admission of patients to home hospice care. Only one respondent describes the procedure differently: 'I do not have a completely stable procedure, I improvise according to the needs of the team and the situation in the family' (respondent 7).

\section{Respondents' own mistakes when admitting a patient to home hospice care}

When asked about the respondents' own mistakes which can complicate the work of others in the team, four respondents state imperfect administration, namely writing data to the electronic system: some missing social data, contacts to relatives, no patient's general practitioner, etc. Three of the respondents are aware of the discussion on better documentation management. They try their best but most of the time they do not catch up: 'Sometimes I write only basic data and go to the field. Then I do not manage. Sometimes I forget' (respondent 8). The other three respondents do not know about mistakes but would like to talk about this topic within the team to correct any mistakes. 'No one has complained significantly so far but I would like to discuss it, for example, at a supervision or a meeting' (respondent 2). Two of the respondents stated that they often have a delay when working for the team due to a part-time contract arrangement. They are not able to change anything about this. They do not catch up with a significant amount of work during their working hours. This could affect the quality of the work only. However, this would be desirable neither for patients nor the home hospice care team.

\section{Inadequate practices of other members of the home hospice care team}

Part of the interview focused on what procedures carried out by colleagues (concerning the patient's admission to home hospice care) are not good and why. Six of the respondents mentioned the need for faster and more operational team cooperation. They are often bothered by the lengthy admission process and the resulting time lag for the patient. 'Slow teamwork and low flexibility due to part-time work contracts' (respondent 2). Four respondents reported an unsatisfactory procedure caused by haste when someone was trying to help as quickly as possible. If it is not possible to correctly estimate the situation during the first visit to the family (that is, whether they will manage the patient's care at all), then there are stressful situations for both the patient and his family and for the home hospice care team. The consequences of such an admission are difficult. They are solved operatively - usually the patient is transferred to an in-patient hospice.

\section{Proposals for changes for an easier patient admission process to home hospice care}

At the end of the interviews, the respondents were asked what would personally help them in the process of admitting a patient to home hospice care. The reactions of respondents pointed out the requirement to introduce the rules, methodology, standards, IT system, that is, they required the elements which would clearly determine the optimal course of the admission process. 'Probably some standards about what exactly to ask at the first contact, and also communication with the team about mistakes and about better solutions for issues' (respondent 3). 'Some IT system shared by everyone where I write information and everyone sees it immediately' (respondents 2, 4, 6, and 7 answered similarly). There were many ideas and wishes in the interviews. Some were heard repeatedly. It can be concluded that it would be appropriate to consider the introduction of some changes arising from the needs of respondents. Some also suggested to introduce a valid routine that would support faster operational cooperation of the team between professions - an operation 
that would be provided by sufficient staffing. In this way it would be possible to respond to the requirements of a multidisciplinary team doctor - nurse - social worker - psychologist without delay. Four of the respondents stated that the certainty of operative consultation with a doctor would help them. This represents a flaw of the home hospice care. There are mainly personnel reasons for this as there is a lack of doctors. Each member of the team has a system for proceeding during the admission of the client to home hospice care. However, these systems are individual, often even situational. In fact, they are not guided by any methodology. The situational interaction of these individual systems can lead to certain problems which then complicate the work of other team members. It is this moment - agreed by the members of the research team - that could be potentially improved by the implementation of the Australian patient admission standards.

\section{Why the Australian Standards?}

The question remains regarding the reason why 'the Australian standards for working with the patient's family' were chosen. This choice was preceded by a study of the available literature and consultations with experts in the field of hospice and palliative care. The main benefit of this choice was the fact that the Australian standards are intended for all palliative patients regardless of the original diagnosis. They differ from most other standards issued in Germany, Ireland, Canada, and USA, which are aimed primarily at cancer patients. Given the situation where the age structure of the population of the Czech Republic belongs to the European average but will gradually become one of the countries with the oldest population according to statistical criteria, ${ }^{13}$ we must take this outlook of a rapidly aging population into account. In practice, this means that even today it is possible to observe a slight increase in applicants for home hospice care due to geriatric fragility. So far, geriatric patients requiring specialised palliative care do not outnumber cancer patients but we must be prepared for this trend as the care of these patients is different in all respects. Although death after a certain age is a foreseeable and natural phenomenon, humans are never prepared for it. The multi-professional home hospice care team faces completely different problems in younger cancer patients and older polymorbid patients. For cancer patients, usually at a younger age, the team helps to address the issues of a person affected by the disease at a productive age. Often there are small children left behind, and unresolved problems. The patient often deals with the question of why the disease has affected him, etc. In elderly geriatric patients, it is necessary to address the correct setting of medication to which patients respond completely differently than cancer patients. We perceive a difference here in the care of the mental state of a senior and in the provision of quality nursing care. We also see different demands concerning the care of the bereaved, especially if the other partner remains completely alone. On the other hand, seniors tend to have most financial and property issues resolved and do not need help in this area. All of these specifics and differences of care are well addressed in Australian standards. These are still living, continuously used methods, operatively evolving according to the current needs of patients. They include demographic and cultural aspects of all regions of Australia. The standards are published repeatedly in new updated versions.

Another argument for using Australian standards is the fact that they are the basis for many other national palliative care societies, including the multinational European Association for Palliative Care (EAPC), in the process of developing palliative care standards and norms in their country.

13 Anna ARNOLDOVÁ, Sociální péče, Praha: Grada Publishing, 2015, p. 136. 
They are also referred to in palliative care standards in Canada. ${ }^{14}$

\section{Australian Standards for Working with the Family}

Clinical Practice Guidelines for the Psychosocial and Bereavement Support of Family Caregivers of Palliative Care Patients (paraphrased): $:^{15}$

1. Once a patient has agreed to receive palliative care, inform the patient that the role of palliative care is also to support their family caregiver(s). The family caregiver(s) will be a person(s) whom the patient perceives to be their most important support person(s). This may be a family member, partner, or friend, and may not necessarily be his next of kin.

2. Ask the patient to identify the primary family caregiver(s). Where only one family caregiver is identified ask the patient if there is another family member / friend who may be willing to be approached and act as an additional family caregiver. Discuss the patient's preferences for the involvement of the family caregiver in medical and care planning discussions and note this in the medical record / care plan.

3. Confirm with the family caregiver(s) that they understand the patient has nominated them for this role. Explain the typical role and responsibilities of 'family caregiver' and confirm they are willing to accept this responsibility and note this in the medical record. Discuss any concerns that the family caregiver may have in accepting this role (including possible conflicts with other family members).

4. Discuss advance care planning with the patient and family caregiver(s) covering any implications relating to the legal responsibilities of the family caregiver(s).

5. Recognise the family caregiver(s) as an important source of information about the patient. Gather information from the family caregiver(s) about their experience as a support person for the patient, including any information (where pertinent) regarding the patient, which they believe may be important for the health professional team to know about.

6. Explain to the family caregiver(s) what services and resources can be provided by the palliative care service so that realistic expectations are established.

7. Whenever possible, convene a family meeting / case conference, including the patient, if practicable.

8. Conduct a needs assessment with the family caregiver(s). This should include psychological and physical health, social, spiritual, cultural, financial, and practical elements.

9. Once the needs of the family caregiver(s) are assessed, develop a plan of action with involvement from the family caregiver(s). Initiate the appropriate interventions as pertinent.

10. Based on discussion with the family caregiver(s), determine the current state of and risk for poor psychological health and/or prolonged grief and plan relevant intervention(s).

11. When appropriate, assist the family caregiver(s) in how to recognise signs that death may be imminent and the potential implications for the patient's care requirements.

12. When death appears imminent, ensure the family caregiver(s) are aware and assess preparedness for death.

13. Confirm with the family caregiver(s) the type of support they may desire in the lead-up to

14 (c) CHPCA, The Canadian Hospice Palliative Care Nursing Standards (on-line), available at: http://www.chpca.net, cited $5^{\text {th }}$ June 2017.

15 Peter HUDSON et al., Guidelines for the psychosocial and bereavement support of family caregivers of palliative care patients, Journal of Palliative Medicine 6/2012, pp. 696-702. 
death (e.g., last hours, days) and/or immediately after.

14. The interdisciplinary team identifies a means of communicating with the family caregiver(s) to determine short-term and long-term post-death responses. Potential external bereavement support services are identified, if required.

15. Relevant members of the interdisciplinary team are advised of the patient's death in a timely fashion.

16. As soon as practicable after the patient's death, a member of the interdisciplinary team should contact the family caregiver(s) to offer condolences and respond to queries. If death occurred at home, assess the need for a home visit.

17. Contact the family caregiver(s) and other family members (as appropriate) to assess needs at three to six weeks post-death and adapt bereavement care plan accordingly.

18. Develop a preliminary bereavement care plan based on the needs of the family caregiver(s), the pre-death risk assessment, and the circumstances of the death (e.g., unexpected or traumatic).

19. Conduct a follow-up assessment of the family caregiver(s) and other family members (if appropriate) six months post-death.

20. Following the death of a patient, the interdisciplinary team should have a discussion (at an appropriate time) about the quality of care provided to the patient and family caregiver(s) and the nature of the death.

\section{Phase No. 3: Selection of Standards for Implementation (3A, 3B)}

The interviews included four questions on the Australian standards for family work. The attitude of individual members of the home hospice care team to the possibility of using the Australian standards in their own organisation was ascertained. The attitudes were mostly positive. Four respondents saw the possibility of testing the standards as a potential benefit and inspiration. Three respondents expected that the possible implementation of the new standards would provide them with knowledge and clearer rules for the admission process. One of the respondents saw this as an opportunity to try inspiring rules which he himself lacks in his work in a team. He said that although the team works in a similar spirit, it does not have such rules officially established. With a growing team, he himself would welcome official rules. Especially, new colleagues are confused and need to learn from others - something from everyone, being what suits them best. One of the respondents stated that every point of the Australian standards can be used in the Czech Republic. There is nothing in them that would limit the team. Another respondent believed that 'the use of the Australian standards in the team would be inspiring and bring systematic work' (respondent 10).

The aim of the individual interviews was, among other things, to find out the mood of the home hospice care team at that moment, to evaluate whether the current way of admitting patients was fully functional, or whether there was a will to think about changes. There was also a need to evaluate respondents' attitudes towards the Australian standards for working with the family and to evaluate their willingness to personally try some of the standards in their own practice.

The result of the analysis of individual interviews was finding out that the team is a compact organism. It cooperates operatively, and is always able to negotiate. The first priority of the team is the maximum quality of patient care in all aspects as it is based on the values of hospice and palliative care. The team members perceive the space to improve their own set processes in the patient's admission to home hospice care. Respondents are willing to invest their time and energy in implementing Australian standards. They expect benefits of inspiration for possible changes to 
the current admissions process.

The use of Australian standards in one's own team is perceived by five members as a possible contribution to the optimalisation of the system and order in the process of admitting a new patient. They hope that, thanks to the implementation, they will create a kind of framework for admission which can be used for the entire team. Three of the respondents see specific positives in focusing on systematic care for mourners from six weeks to six months after death. At present, except for meetings of the bereaved twice a year, they deal with it rather intuitively. In Australia, they care for the bereaved to a greater extent than in the Czech Republic. They also discuss their reflections on mourners, they learn from possible mistakes. The team could put more emphasis on that. Two of the respondents see an opportunity in focusing on caring for the family as a whole. They would like to pay more attention to the care of mourners and map the whole situation in the family in detail.

One of the questions in the semi-structured interview asked the respondents to choose four of the Australian standards they would like to try in a real three-month implementation - preferably those that are lacking in the current system of work procedures, that is, the ones that would be most useful and effective in their view.

Table 3 provides an overview of twenty standards according to how the respondents chose them for possible implementation. In the first line we find the series of numbers of all twenty Australian standards listed above. The second line records how many respondents selected a particular standard for implementation. The table shows that the respondents chose standards Nos. 2, 9, 18, and 20 the most (namely four times).

Table 2: Frequency of standards chosen for implementation

\begin{tabular}{|l|l|l|l|l|l|l|l|l|l|l|l|l|l|l|l|}
\hline \multicolumn{1}{|l|}{ Frequency of selected standards: } \\
\hline Standard number & 20 & 18 & 2 & 9 & 19 & 14 & 4 & 5 & 13 & 3 & 6 & 10 & 16 & 1 & 7 \\
\hline Frequency & 4 & 4 & 4 & 4 & 3 & 3 & 3 & 3 & 2 & 2 & 2 & 2 & 2 & 1 & 1 \\
\hline
\end{tabular}

Source: Own processing

The team members were acquainted with this conclusion of the analysis at the next regular joint meeting of home hospice care. This analysis was one of the main indicators for the next implementation process. It was a supporting point for the consensus of the whole team when selecting specific Australian standards for the three-month implementation. The team members reiterated the standards, discussed their detailed focus, consulted and presented their views, and finally made sure that the standards would be used by the team in its actual operation. The trial period was set from 1 September to 30 November 2017. Nine out of ten original respondents actively participated in the implementation. One respondent declined to cooperate due to serious time reasons.

\section{Phase Nos. 4 and 5 (4A-5B): Implementation Process and its Reflection}

The fourth stage of the research, that is, the implementation phase itself, took place in the period from September to November 2017. During the first month of implementation, 12 admissions to home hospice were realised (during the second month it was 5 , and during the third 
month it was 4). A total of 21 patients were admitted to home hospice care while using elements of the above-selected Australian standards for working with the family. Throughout the implementation period, the team members addressed regular ambiguities, uncertainties, fears, observations, and positive experiences during regular meetings. Throughout the implementation period, the team members communicated with each other on an ongoing basis and reflected upon the ongoing process.

One team meeting was then intended for an overall evaluation of the previous experience. The experience concerned the implementation of standards for patient admission, including in the form of a group interview. Eight out of nine implementation participants met within the set deadline. All participants actively participated, collaborated, and realistically suggested or argued regarding the experiences they had during the past three months. During the implementation period, which lasted 91 days, 21 patients were admitted to home hospice care. During those admissions, the standards were tested practically.

The team members appreciated the method of implementation, especially the detailed explanation of the reasons and the method of its implementation, as well as sufficient time to absorb information about Australian standards. Most participants worked well with the standards and perceived them positively.

On the question of the applicability of standard 2, four respondents were positive, two positive with reservations, and two were negative. However, the team as a whole would welcome the introduction of this standard in their organisation - the team members agreed that it would make it easier for them to work within the team, especially in the area of passing on information about the client / client's family. Negative reactions to this standard included concerns about increased administration and increased time taken.

Six participants commented unequivocally positively on the second implemented standard (9). All of them considered it necessary to implement such a standard in the organisation. One respondent considered the introduction of a similar standard to be unnecessary.

The third standard (18) provoked a lively debate. The conclusion was seven positive attitudes toward implementation and one negative, arguing as follows: 'And again, this is about the risk factors. I've had enough. I'm not a clairvoyant. If one wants to predict responsibly the unpredictable, it is like solving the unsolvable. I leave it to the development of the situation in the family' (respondent 2). However, most thought in a similar vein to respondent 7: 'This is a harder to grasp but necessary standard. The question is what is the best way to grasp it so that it is a usable standard in our country. Especially, it is necessary for measuring the quality of services provided by our team.' This standard was therefore also perceived as beneficial for improving the quality of services provided. Six respondents commented positively on the last implemented standard (20), that is, in favour of its implementation. Respondent 5 responded with reservations: 'I do not share your enthusiasm, I still have a problem with terminology. What exactly is "a good time"? I am in favour of a clear specification, and then I would agree.' And respondent 8 mentioned concerns: 'I'm just worried that we will end up drowning in all those papers. I am in favour of introducing concise, clear, well-arranged, effective, and meaningful standards.' Concerning the statements of the respondents, it was clear that the tested standards were perceived positively on a practical level - that is, as beneficial for better coordination of teamwork and thus for higher quality of services provided. The reservations concerned both terminological ambiguities and time-related concerns associated with the implementation of the selected standards.

The group interview also focused on the possible interest of the team in introducing a change in 
the field of standards, the incorporation of some of these tried and tested standards into practice. When asked whether everyone was well acquainted with the issue and the intention, and whether they understood the reasons for this possible change, the respondents generally responded in agreement. No one fundamentally opposed - the team members perceived the implementation of the selected standards for working with the family as beneficial for better coordination of the work of the team as a whole.

\section{Recommendations for Practice, Conclusions}

Given that the home hospice team has been actively and genuinely involved in the research, it can be assumed that there is space for real reflection upon the introduction of change. During the research and implementation process, it has been shown repeatedly that the team is a compact, living organism. It tries to do its best in all circumstances to maintain quality functioning. Based on the results of individual interviews and group interviews, the following recommendations were made - although it is based on the needs of a particular organisation, we believe it could be an inspiration for other multidisciplinary teams, especially those which consider organisational change in order to streamline teamwork and improve service quality:

- If an organisation decides to implement change, the whole process needs to be well timed, prepared, and implemented with the right steps so that it has a chance of success. The home hospice team is a functioning organism that is sensitive to all stimuli. We perceive that a directive change 'from above' is not appropriate here, for example, in the form of a change in methodology without any consultation.

- During the preparatory phase of the change process, we recommend finding out the state of the organisation's readiness for the change implementation first. For example, one should use some of the tools 'to analyse the situation and identify the factors that support the process of change (accelerators), and the factors which block it (retarders). This is called a force field analysis. Accelerators and retarders have the opposite orientation with different intensities. After assessing their significance, it is possible to decide about the change or stay in the current state.16

- We recommend remaining with proven models when compiling a change implementation plan. For example, it would be possible to use the method 'Eight steps of successful transformation of the organisation. ${ }^{17}$ We have already taken the first step of this method within the research, namely the introduction of the idea of change implementation. The second step of the method is to build a stable team of the most motivated people. It is necessary to explain to this team what will happen and why, clearly and intelligibly. It is also important to give staff relevant time to receive this information and to check that there has really been enough time. In his method, Kotter also recommends conveying the idea to all employees, elaborating a detailed procedure for implementing changes, and answering all the questions asked. Kotter's fifth step is then the implementation itself where it is recommended to set the necessary adjustments according to current requirements. Here, we recommend adjusting the standards into a precise, usable, and effective wording for the team. The sixth step of the method is to set short-term goals. In this way, it is possible to point out the partial successes of the team, motivate employees to continue the started process with maximum support,

16 Lada FURMANÍKOVÁ, Studijní opora ke kurzu Teorie a praxe řizení organizací. Unpublished manuscript, Praha: UK FHS, 2017.

17 John P. KOTTER, Vedení procesu změny, Praha: Management Press, 2000. 
and work for a long time to stabilise the change so that the original stereotypical state does not return. The seventh step is to consolidate the change achieved so that it becomes an automatic part of the team's work process.

- The final recommendation is to map out the potential risks that could complicate the successful implementation of the change. It is about finding ways to prevent risks or looking for ways to solve problems that could occur. The research revealed the team's concerns, especially about the lack of time, insufficient staffing, stress from the news, and from the fact that employees will not know how to properly understand the change.

The fundamental experience we have gained through the implementation of this project is that any process in an organisation, team, or company requires enough time for all processes, even for thinking about the change. The process of organisational change related to work procedures, where routine - learned behaviour - is being changed, is an activity for at least a few months, but rather for several years. We self-critically believe that in order to increase the probability of success, it would be appropriate to involve members of the home hospice care team in the research preparation process itself.

We believe, based on a collective reflection at the end of the implementation process, that the incorporation of selected standards has triggered a deeper thinking of multidisciplinary team members on all possible ways to improve, simplify, speed up, and refine work coordination - and thus increase the quality of services provided. The project presented by us can also be perceived positively: it initiated a collective reflexive process which focused the attention of team members on such important topics as the effectiveness of work procedures, quality of services provided, coordination of work in a multidisciplinary team, etc. The participation of respondents in the research stimulated their activity in a discussion with other team members who did not directly participate in the implementation, but only observed the resulting effect. Respondents were most significantly influenced by their own experience with this experiential method. The team especially appreciated the time allowed for the individual steps which was needed in order to absorb new information and understand why this is happening. The whole process created the feeling that they needed change in the team. This is an essential moment for the possibility of success of any change process in an organisation. One of the most important effects of the described implementation process is that the team members, through a shared reflective process, recognised the need for changes in the team. They saw them as beneficial, and that they save time by eliminating the duplication of tasks, etc.

We can answer in the affirmative about the applicability of Australian standards to other home hospice teams. This is possible due to the similarity of procedures and work system which must adhere to the applicable legislation and conditions for the operation of these specific services. Therefore, we can offer the research results as inspiration to other teams across the country. Working in a home hospice can be seen as 'death before me, death behind me'. We would hardly find a more striking slogan characterising this profession. From the point of view of a nurse with six years of hospice care experience, the co-author of the article perceives this service as meaningful and very sought after. Promoting humanity and dignity in the final stages of life is the only guarantee of maintaining the maximum quality of life for as long as possible. Although hospice and palliative care in our country does not have a long history, it is certain that its importance will grow as the Czech population is aging. 
$115 \frac{10}{2020}$

\section{Contact}

\section{Naděžda Adámková MA}

Charles University

Faculty of Humanities

Department of Management and Supervision in Social and Health Care Organisations Pátkova 2137/5, 18200 Praha 8 - Libeň

nadezda.adamkova@cestadomu.cz

\section{Dr. Michal Růžička}

Charles University

Faculty of Humanities

Department of Management and Supervision in Social and Health Care Organisations Pátkova 2137/5, 18200 Praha 8 - Libeň

ruzicka.michal01@gmail.com 